\title{
Habitat selection by American beaver at multiple spatial scales
}

\author{
Guiming Wang ${ }^{1 *}$, Lance F. McClintic ${ }^{1,2}$ and Jimmy D. Taylor ${ }^{3}$
}

\begin{abstract}
Background: Semiaquatic mammals require both aquatic and terrestrial habitats, particularly interfaces between the two habitats. As ecosystem engineers, American beaver (Castor canadensis) consume and fell a great amount of deciduous trees. We tested the prediction that open water and amounts of food resources, including hardwood forests (i.e., deciduous trees as the dominant form of vegetation), herbaceous and woody wetlands, and shrubs, would influence the second-order habitat selection (i.e., placing home ranges on the landscape) by American beaver, whereas the third-order habitat selection of American beaver would be associated with woody wetland and shrub edges. We investigated hierarchical habitat selection by American beaver using location data from very high frequency telemetry. Dirichlet-multinomial models were used to determine the second-order habitat selection at landscape scales. Bayesian spatial resource selection function was used to assess the third-order habitat selection within home ranges.

Results: Second-order habitat selection by American beaver was associated with herbaceous wetland, shrubs, hardwood forest, grassland, and woody wetland more than open water bodies at landscape scales. At the third-order scale, American beaver selected herbaceous wetlands as well as the edges of shrubs and woody wetland within established home ranges.

Conclusions: Spatial distributions of food resources affected both the second- and third-order habitat selection by American beaver. Herbaceous wetlands were more important habitat components than water bodies in the secondand third-order habitat selection by American beaver. Dirichlet-multinomial distribution models for the second-order habitat selection and Bayesian spatial resource selection functions for the third-order habitat selection do not need pseudo-absence locations, providing alternative approaches to the presence-absence methods for habitat selection by animals.
\end{abstract}

Keywords: Castor canadensis, Dirichlet-multinomial model, Second-order habitat selection, Spatial resource selection function, Third-order habitat selection

\section{Background}

Animals often exhibit hierarchical habitat selection across different spatial scales $[1,2]$, in which multiscale selection may be influenced by different ecological factors or processes [3]. Semiaquatic mammals live part of their life on land and require aquatic habitat to meet their seasonal and annual habitat requirements [4]. The distributions of home ranges and populations

\footnotetext{
*Correspondence: guiming.wang@msstate.edu

${ }^{1}$ Department of Wildlife, Fisheries and Aquaculture, Mail Stop 9690,

Mississippi State University, Mississippi State, MS 39762, USA

Full list of author information is available at the end of the article
}

of such semiaquatic animals throughout the landscape may rely on the availability of open water bodies (e.g., lakes, swamps, sloughs, rivers, or streams). Semiaquatic mammals, particularly those occupying dens or lodges in water, may depend on water for protection against predators [4]. Semiaquatic capybaras (Hydrochoerus hydrochaeris) intensively use the water-land interface of high-quality, abundant forage, avoiding areas distant from water bodies [5]. Beaver (Castor sp) forage in water and on land approximately $100 \mathrm{~m}$ from water's edge [6, 7], and forage availability influenced habitat selection by semiaquatic Eurasian beaver (Castor fiber) at both fine and large spatial scales [8]. Fine-scale habitat selection 
(i.e., third order or within home ranges) by semiaquatic mammals, particularly herbivores, may depend on the distributions of food resources in proximity to water [5, 9]. Therefore, semiaquatic mammals may exhibit hierarchical selection across the second-order (i.e., placing home ranges in or nearby water bodies to avoid predation risk and in the area of abundant forage) and the third-order (i.e., selecting the location of abundant forages within home ranges) habitat selection [2].

American beaver (Castor canadensis) are semiaquatic herbivorous mammals that feed on deciduous trees, shrubs, and aquatic plants [10-12]. American beaver also fell trees and cut seedlings to build dams to impound water and create ephemeral, herbaceous wetlands [12]. Herbivory and dam construction by American beaver may substantially modify the composition and physiognomy of forest communities and landscapes [13, 14]. Water impoundment, bark stripping, and logging by beaver may create forest openings and herbaceous wetlands and enhance shrub abundance [15]. American beaver are also central place foragers with their feeding being restricted to the riparian within $60 \mathrm{~m}-100 \mathrm{~m}$ from their lodges or dens in water bodies [16]. However, no studies have evaluated the roles of food resources (e.g., deciduous trees and shrubs) and water bodies in the secondorder habitat selection and compared the second-order to third-order habitat selection by American beaver.

Studies of habitat selection by American beaver have primarily focused on the characterization of dam and lodge site selection or occurrence of beaver colonies using the presence-absence or presence-pseudoabsence approaches in the USA [11, 12, 17, 18]. Touihri et al. [19] identified 12 peer-reviewed articles regarding the habitat models of American beaver out of 1500 total articles from ISI Web of Science and ScienceDirect with the keywords "beaver" AND "habitat" OR "model." All of the 12 articles used response variables of the presence/ absence or densities of beaver dams, lodges, or colonies [19]. Recently Holland et al. [20] used occupancy models to predict the occupancy probability of American beaver in southern Illinois, USA, using tracks and signs of the beaver, including dam and lodges. However, they did not investigate habitat selection by American beaver at multiple spatial scales. Several studies have investigated hierarchical habitat selection by Eurasian beaver using available-use approaches such as multivariate statistics, compositional analysis, K-select methods, and resource selection functions [8, 21-23]. Steyaert et al. [7] evaluated habitat selection by Eurasian beaver using the relocations of global positioning system (GPS) transmitters and resource selection functions. Francis et al. [17] used population-scale presence locations of American beaver and maximum entropy (MAXENT) models to investigate landscape- and population-scale habitat selection, and also used GPS location data and generalized additive models to assess the third-order habitat selection by American beaver. However, Francis et al. [17] did not assess the second-order habitat selection by American beaver.

Second- and third-order habitat selection by animals is often assessed with use-availability and the presenceabsence approaches [24, 25]. Given difficulties in collecting "true" absence location data, randomly sampled points are used as pseudo-absence locations to quantify resource availability [26]. For example, locations randomly selected within the minimum convex polygon (MCP), which encompassed all the GPS locations of all relocated individuals, were used to quantify available resources for assessing the second-order habitat selection by white-tailed deer (Odocoileus virginianus) [27]. An index of the second-order habitat selection, with the ratio of resource use within home ranges to availability throughout landscapes, suffers from interdependence among the proportions of all available resources. Although compositional analysis of the second-order habitat selection overcomes the interdependence, it uses the number of tests, in which the log ratio of the use and availability of a resource type is significantly greater than that of another resource type at a significance level, to rank the second-order selection of a habitat type [28]. Nevertheless, the relative ranking does not provide explicit statistical tests for hypotheses regarding the second-order habitat selection.

In this study, we used Dirichlet-multinomial distribution models, a multivariate probabilistic model, to evaluate the second-order habitat selection by American beaver. Dirichlet-multinomial distribution models do not require pseudo-absence locations. We also used Bayesian spatiotemporal models to assess the third-order habitat selection by American beaver accounting for both temporal and spatial autocorrelations of radio-telemetry data [29]. To the best of our knowledge, few studies of habitat selection by wildlife, including American beaver, have considered the spatial and temporal autocorrelations of the presence locations for the third-order habitat selection. Additionally, Bayesian spatiotemporal models assume Poisson distributions for space use intensity, and do not require pseudo-absence location data.

Here we tested two predictions of habitat selection by American beaver in northern Alabama (Fig. 1). First, we hypothesized that availability of both open water bodies and food resources would determine the second-order habitat selection by American beaver. Thus, we predicted that American beaver would select open water body, herbaceous wetland, shrub, woody wetland, and hardwood forest (i.e., deciduous trees as the dominant form 


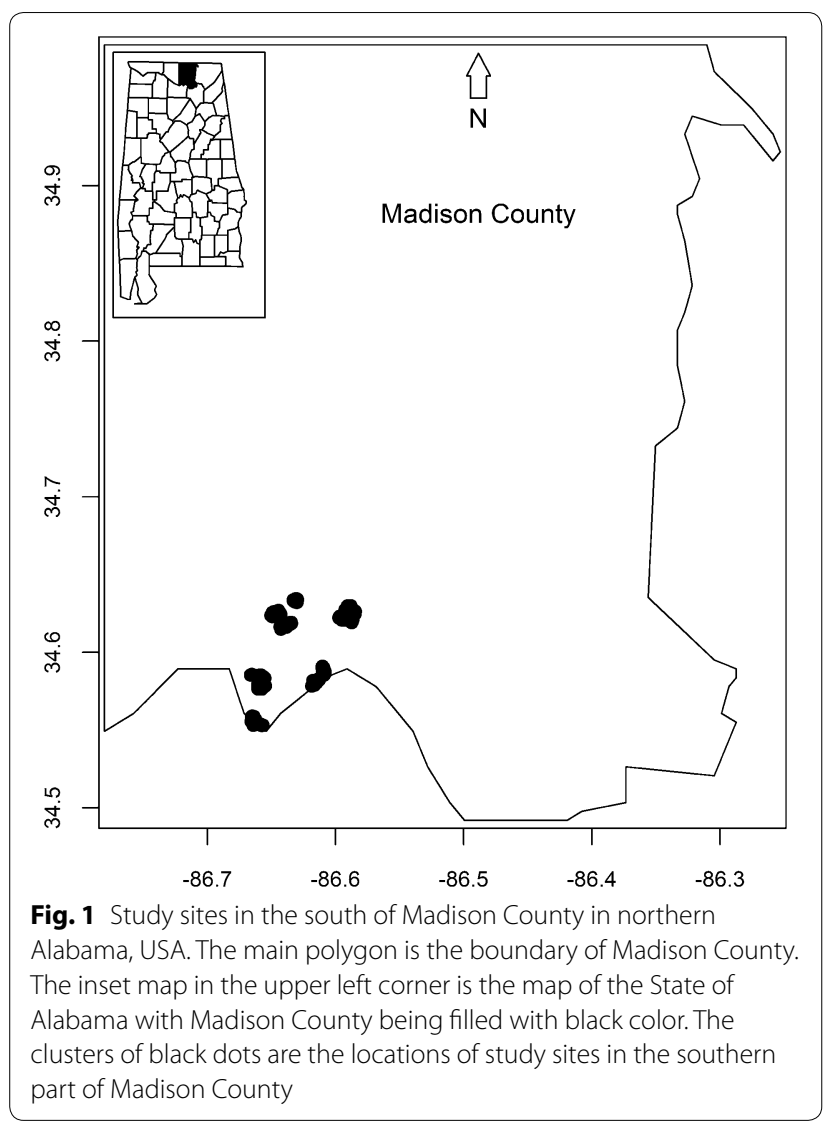

of vegetation) for home ranges on the landscape. Second, we hypothesized that American beaver would select the boundary zone (i.e., forested or woody wetland edge) between hardwood forests, shrubs, and water bodies for the third-order habitat selection because of predator avoidance and spatial distributions of food. Therefore, we predicted that the intensity of fine-scale space use (e.g., the number of presence locations per unit area) by American beaver would be positively related to the edge amount of woody wetlands and shrubs.

\section{Results}

Evidence supported that the second-order habitat selection by American beaver was not random. In the analysis of the second-order habitat selection with Dirichlet-multinomial distribution models, the value of Akaike information criterion (AIC) of the null model for random second-order habitat selection was 875.59 , whereas that of the linear preference model was 696.29. Additionally, the $p$ value of $\chi^{2}$ goodness of fit test was 0.62 for the linear preference model, indicating adequate fit. The values of preference index $h$ indicated that American beaver selected herbaceous wetland $(h=0.49) 3-4$ times more than other LULC types, including open water bodies,

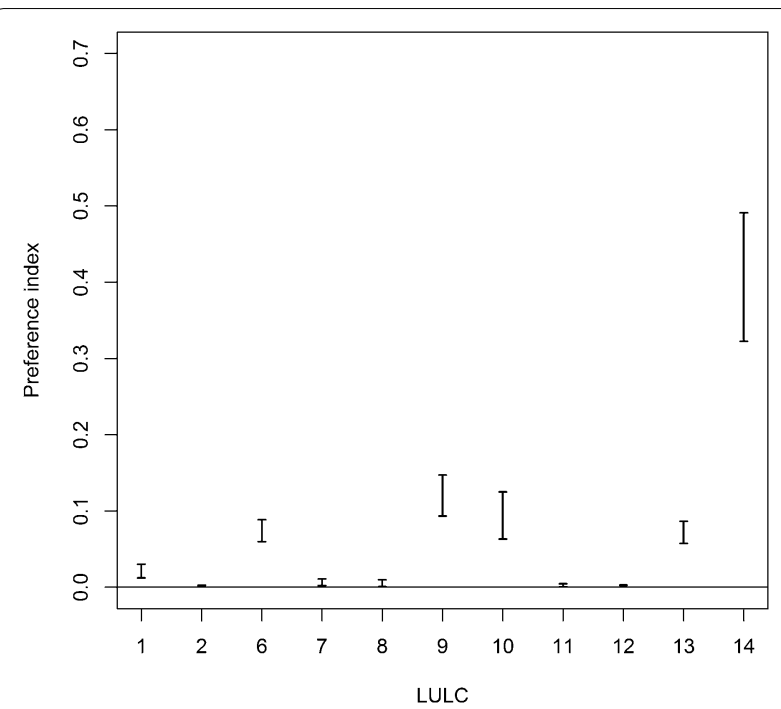

Fig. 2 Habitat preference indices $h$ of 11 types of land use and land cover (LULC) of American beavers. Types (x axis) are open water (1), developed area (2), hardwood forest (6), coniferous forest (7), hardwood-conifer mixed forest (8), shrub (9), grassland (10), pasture (11), crop (12), woody wetland (13), and emergent herbaceous wetland (14). Vertical bars are 95\% confidence intervals

with the $95 \%$ confidence intervals (CI) exceeding those of other LULC types (Fig. 2). American beaver also selected shrub $(h=0.147)$, grassland $(h=0.125)$, hardwood forest $(h=0.089)$, and woody wetland $(h=0.087)$ with the 95\% CIs of preference index $h$ exceeding 0.05 ; however, American beaver did not select developed $(h=0.003)$, agriculture (or crop, $h=0.003$ ), pasture $(0.005)$, coniferous forest $(h=0.011)$, or mixed forest $(h=0.01)$ with the 95\% CI including zero (Fig. 2).

With the forward selection of 30 landscape variables for the third-order habitat selection by American beaver, the best model of the Bayesian spatial resource selection function (BSRSF) had the lowest deviance information criterion (DIC) value of 655.15. The best model included shrub edge density, woody wetland edge density, distance to crop, and proportion of herbaceous wetland. The second best model, which had a $\triangle \mathrm{DIC}$ score 2.1, included shrub edge density, woody wetland edge density, and distance to crop (Table 1). Intensity of the third-order habitat selection by American beaver was positively related to shrub edge density, woody wetland edge density, distance to crop field, and proportion of herbaceous wetland, with the $95 \%$ credible intervals of the estimated coefficients excluding zero in the best model (Table 2).

\section{Discussion}

Occurrences of American beaver colonies are often associated with open water bodies such as rivers, streams, lakes, and ponds $[20,30,31]$. Furthermore, forage 
Table 1 Forward selection of $\mathbf{3 0}$ landscape variables

\begin{tabular}{ll}
\hline Model & DIC \\
\hline Intercept & 663.95 \\
cropdist & 661.06 \\
shrubbd & 661.60 \\
shrubfa & 661.62 \\
cropdist + shrubfa & 658.96 \\
shrubbd + cropdist & 659.24 \\
shrubfq + hwbd & 659.59 \\
cropdist + shrubbd + wwetbd & 657.21 \\
cropdist + shrubbd + wwetbd + hbwetfq & 655.15
\end{tabular}

Step 1 selected single variables, which reduced the deviance information criterion by $>2.0$, to form single-variable models. Step 2 added one of the remaining 29 variables to each of three selected single-variable models, respectively, resulting in three two-variable models which reduced DIC by $>2.0$. Step 3 added 28 remaining variables to each of three resulting two-variable models, resulting in a three-variable model. Step 4 added each of remaining 27 variables to the selected three-variable model and resulted in a four-variable model. All 26 five-variable models had DIC values greater than that of the selected four-variable model

availability influences the spatial distribution and local abundance of American beaver [31, 32]. American beaver select woody wetlands or swamps of diverse, abundant deciduous trees and aquatic plants for their colonies in boreal forests [31]. However, our results demonstrated that the influence of available open water bodies on the second-order habitat selection by American beaver was much less than that of available food resources (i.e., woody and herbaceous plant cover types). American beaver selected herbaceous wetland and the edges of shrubs and woody wetland at the third-order scale, but did not select the edges of water bodies as predicted in northern Alabama. Therefore, availability of food resources appeared to be the main determinant of both the secondand third-order habitat selection by American beaver similar to Eurasian beaver and other mammalian herbivores $[8,33]$.

Although beaver require water to access lodges or bank dens, cache food, and escape predators [12], American beaver exhibited less selection of open water bodies than of herbaceous wetland, shrub, and woody wetland, given the availability of those LULC types (Fig. 2). Furthermore, landscape variables related to open water bodies did not affect the third-order habitat selection by American beaver (Table 2). American beaver are known to exit water for foraging, generally staying within a $60-\mathrm{m}$ distance from water bodies [7, 34, 35].

American beaver selected habitat with abundant emergent herbaceous wetlands at both the second- and thirdorder scales (Table 2, Fig. 2). Hartman [36] found that Eurasian beaver selected herbaceous wetlands as well. The positive association between habitat selection and proportion of herbaceous wetland may be owing to the use of aquatic plants as food by American beaver during spring and summer (or year-round in the Southern USA) when herbaceous plants become available [10, 37]. We were unable to evaluate seasonal habitat selection by American beaver due to inadequate sample size (secondorder habitat selection) and unbalanced sample sizes among seasons (third-order habitat selection). Future studies of seasonal habitat selection are needed for better understanding of habitat selection by American beaver at fine temporal scales.

American beaver selected hardwood forests at the second-order scale in our study area (Fig. 2). American beaver feed on deciduous trees and shrubs in the boreal and riparian forests [35, 38]. However, availability of hardwood forest, indexed by proportion of hardwood forest, did not affect the third-order habitat selection by American beaver. Amount of woody wetland edge was correlated with intensity of space use at the third-order scale, consistent with previous observations that foraging of American beaver was restricted to the interface between hardwood forests and water bodies, which was located in woody wetland [16]. Eurasian beaver also selected deciduous forests and shrubs at the edge of water bodies [23]. Assessments of multi-scale habitat or resource selection, such as the analyses we performed in this study, are

Table 2 Coefficients of landscape variables of the most parsimonious Bayesian spatial resource selection function model of American beavers

\begin{tabular}{lcccc}
\hline Coefficient & Mean & SD & 95\% Cl lower limit & $\begin{array}{c}\text { 95\% Cl } \\
\text { upper } \\
\text { limit }\end{array}$ \\
\hline Intercept & & & -5.77 & -3.16 \\
Shrub edge density & -4.45 & 0.66 & 0.04 & 0.19 \\
Distance to crop & 0.12 & 0.04 & 0.0009 & 0.0031 \\
Woody wetland edge density & 0.002 & 0.0006 & 0.03 & 0.16 \\
Proportion of herbaceous wetland & 0.09 & 0.03 & 0.24 & 9.92 \\
\hline
\end{tabular}

The coefficient measures the effects of landscape variables on space use intensity (i.e., number of relocations per $120 \mathrm{~m} \times 120 \mathrm{~m}$ grid cell in this study) of American beaver. Initial $\mathrm{Cl}$ stands for credible interval 
unique because they can provide comprehensive understanding of animal habitat selection.

American beaver avoided crop landcover types with space use intensities increasing farther from crop fields at fine spatial scales (Table 2) and had very low values for the second-order habitat selection index $h$ (Fig. 2). Low food values of crops and great distances to crop fields probably deterred the use of crop fields by American beaver. At the second-order scale, American beaver also avoided habitats with abundant mixed forests probably because American beaver avoided conifers as food (Fig. 2) [6]. Restriction of movement in the area of standing or flowing water may also limit selection of crop fields as habitat by American beaver in this area.

Francis et al. [17] estimated habitat selection by American beaver with data on the locations of beaver dams, lodges, feeding stations, foraging locations, castor mounds, and capture locations of spring and summer, relating the relative probability of American beaver occurrence to landscape variables using MAXENT models. Maximum entropy models do not explicitly account for spatial and temporal autocorrelations of location data. In this study, we used the year-round telemetry relocations of 21 beaver to infer the effects of landscape variables on the intensity of space use by American beaver with spatial statistics. Models of Bayesian spatial resource selection functions used in this study quantify the local availability of resources in proximity to each occurrence locations, whereas MAXENT models use a large number of pseudo-absence locations (e.g., $n=10,000)$ across landscapes. Therefore, the consistence of the findings between the two studies, which used different sets of location data and different analytic methods, produced the robust conclusions of habitat selection by American beaver. Furthermore, neither multivariate probability models of Dirichlet-multinomial distributions nor resource selection functions of Poisson distributions require using pseudo-absence locations to quantify availability of resources, representing alternative approaches to resource selection functions and habitat selection models.

\section{Methods}

\section{Study site}

Our study site was located in northern Alabama (Fig. 1) and was relatively flat (elevation: 165-365 m). Land use and land cover classes consisted of agricultural (or crop) field, developed (e.g., military test ranges, roads, and buildings), bottomland hardwood forest (or woody wetland), hardwood forest, coniferous forests, mixed forests, open water body, and emergent herbaceous wetlands [39]. The spatial distribution of the LULC types across the landscape can be found in Fig. 1 of McClintic et al. 2014 [40].

\section{Beaver capture and radio-telemetry}

We reanalyzed very high frequency (VHF) telemetry relocation data of American beaver at Redstone Arsenal (RSA) in Madison County, Alabama (AL), USA [39]. American beaver were captured from 11 wetlands located in the southern half of RSA from January to May 2011 [40], using Hancock live traps (Hancock Trap Company, Custer, South Dakota, USA). Traps were activated daily before $1500 \mathrm{~h}$ and checked the following morning

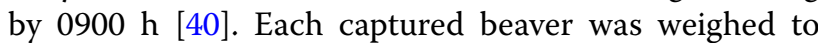
the nearest $0.1 \mathrm{~kg}$ using a hanging scale (Moultrie Feeders, Alabaster, AL, USA). Yearling, subadults, and adults $(>6.8 \mathrm{~kg})$ were attached with VHF radio-transmitters (Model 3530, Advanced Telemetry Systems [ATS], Isanti, Minnesota, USA).

Twenty-six radio-tagged American beaver were monitored $\geq 2$ times per week from May 2011 to July 2011 and once every 2 weeks from August 2011 to April 2012 using radio-telemetry [41]. Radio-tagged American beaver were located during the active hours of $1800-0600 \mathrm{~h}$ with an ATS 3-element hand-held Yagi antenna, an R-1000 receiver (Communications Specialist Inc., Orange, CA, USA), and a look-through compass (Model KB-20/360R, Suunto, Vantaa, Finland). Universal Transverse Mercator (UTM) coordinates were estimated for each beaver location with three or more azimuths per animal with an overall separation of $60^{\circ}-120^{\circ}$ in $\leq 15 \mathrm{~min}$ and adjusted for $3^{\circ}$ declination using triangulation methods [42] within the program LOCATE III [43]. Twenty or more individuals are recommended sample sizes for resource selection studies [44, 45]. Location data collected from 21 of 26 radio-tracked American beaver, which had a minimum of 30 recorded locations per individual over the entire study period, were used for habitat selection analyses in this study. The remaining five radio-tracked beaver had less than 30 relocation points and were excluded from analyses. We did not conduct seasonal analysis of habitat selection because our location data did not meet the recommended sample size (i.e., 20 or more individuals and 30 or more locations per individual per season). All locations used in this study had a $95 \%$ error ellipse $<0.5$ ha [39].

\section{Land use and land cover maps}

The National Land Cover Database (NLCD) 2011 (www. mrlc.gov/nlcd2006.php) was used to derive LULC maps at $30-\mathrm{m}$ resolution for the study area [46]. The original four levels of developed class (class 21-24) were combined into one class (i.e., developed area). The resulting 
11 LULC types for the second-order habitat selection analysis included water (or open water bodies), developed area, deciduous forest (or hardwood forest), coniferous forest, mixed forest, shrub, grassland, pasture, crop, woody wetland, and herbaceous wetland. We used the NLCD 2011 to generate three rasters for each LULC class: relative frequency $(0-1)$ within a circular buffer of each LULC class, distance to the nearest grid cell of each LULC class, and edge density [total length $(\mathrm{m})$ of edge $\mathrm{ha}^{-1}$ ] within a circular buffer of each LULC class, producing a total of 30 landscape variables for the thirdorder habitat selection analysis with grassland and pasture combined. We used a circular buffer of six 30-m grid cells, equivalent to annual home range size [40], to generate the relative frequency and edge density rasters using the programs CircAn within software BIOMAPPER 3.2 [47]. Relative frequency was calculated as the proportion of a circular buffer (i.e., the number of total grid cells or total area within the buffer) which is occupied by a LULC class. We used program CircDist of BIOMAPPER to generate the distance of a grid cell to the nearest cell of a LULC class. We resampled 30-m landscape rasters to $120-\mathrm{m}$ rasters $(120 \mathrm{~m} \times 120 \mathrm{~m})$ for BSRSF analysis to reduce the computational burden. We selected the spatial resolution of $120 \mathrm{~m}$ for BSRSF analysis to match the average hourly movement distance (about $118 \mathrm{~m} \mathrm{~h}^{-1}$ ) of American beaver on our site [40]. The spatial resolution of the raster was equivalent to about $6-12 \%$ of annual home range (about 12-21 ha) on our site.

\section{Statistical analysis}

We first used the available-use approach to estimate the second-order habitat selection to determine which LULC classes influenced the second-order habitat selection by American beaver. Then we used BSRSF to determine the selection of landscape variables at fine spatial scales.

We used Dirichlet-multinomial distribution models to determine the second-order habitat selection by American beaver [48]. The distribution of location counts over different LULC classes was assumed to follow the multinomial distribution. The probability of selecting a LULC class was assumed to have a Dirichlet distribution [48]. Dirichlet-multinomial distribution models can be implemented in two different models to represent different hypotheses concerning habitat selection among individuals under identical availability [48]. The first model assumes that animals randomly select resources or habitats (i.e., the null hypothesis). The second model assumes that habitat selection is proportional to resource availability times a type-specific linear preference coefficient or index $h(h>0$ and $\Sigma h=1$; i.e., linear preference hypothesis). The Dirichlet distribution with an $h$ index also absorbs individual heterogeneity in location counts. Resource availability was measured by the proportion of LULC classes across the entire study area, calculated using 30-m NLCD rasters. The greater the coefficient $h$ for an LULC class, the stronger the selection for the LULC class. Unknown parameter $h$ for each LULC class was estimated by maximum likelihood methods using the $\mathrm{R}$ code provided in de Valpine and Harmon-Threatt [48]. We used AIC to compare the random selection and linear preference models. Bootstrapping methods were used to estimate empirical 95\% CI for each selection coefficient $h$ ( $n=2000$ iterations). We assessed goodness of fit of the selected model using chisquare $\left(\chi^{2}\right)$ test [48].

Bayesian spatial resource selection functions represent the spatial distributions of VHF locations by the use intensity per grid cell. The BSRSF model assumes inhomogeneous Poisson distributions and relates the intensity of space use to landscape variables in each grid cell [29]. The BSRSF accounts for spatial autocorrelation using conditional autocorrelative (CAR) distributions in the framework of small area models [49]. The natural logarithm of the Poisson parameter $\lambda$ (i.e., mean use intensity or mean location count per grid cell) is a linear function of landscape variables $\left(\mathbf{x}(\mathbf{s})^{\prime} \mathbf{\alpha}\right.$ of Eq. 1) plus spatially structured random effect term of the CAR distribution (i.e., $\eta(\mathbf{s})$ of Eq. 1).

$$
\log \lambda(\mathbf{s})=\mathbf{x}(\mathbf{s})^{\prime} \boldsymbol{\alpha}+\beta_{1} \log G^{\prime \prime}(\mathbf{s})+\eta(\mathbf{s})
$$

Temporal autocorrelation is accounted for by the term $\log G^{*}(\mathbf{s})$ of Eq. 1 [29]. $G^{*}(\mathbf{s})$ is the spatial kernel density of VHF relocations $\mathbf{s}$. The kernel density map of VHF relocations of each individual was generated using a normal kernel of the bandwidth $b=1.96^{-1} v \sqrt{t_{i+1}-t_{i}}$, where $b$ is the bandwidth; $v$ is the hourly movement speed $\left(=112 \mathrm{~m} \mathrm{~h}^{-1}\right)$ of beaver estimated from VHF data [40]; and $t_{i+1}$ and $t_{i}$ are the times (hours) between two successive locations [29]. The BSRSF was implemented in the Bayesian framework using the R package R-INLA [50, 51]. We selected the most parsimonious model using a forward stepwise selection with DIC [52]. The most parsimonious model has the lowest DIC among candidate models. First, we built 30 single-covariate BSRSF models. We selected landscape variables, which reduced DIC by $>2.0$, to build the BSRSFs of two landscape variables, and so on until DIC improvement was $<2.0$ after adding a covariate to the previous best model. We only included one of the two highly correlated landscape variables (absolute Pearson's correlation $|r| \gg 0.7$ ) in the same model. 


\section{Conclusions}

Availability and spatial distribution of food resources may influence habitat selection by herbivores. Spatial distributions of food resources affected both the second- and third-order habitat selection by American beaver on this military installation in North Alabama. American beaver were associated with herbaceous wetland more than with open water bodies in the second- and third-order habitat selection. Dirichletmultinomial distribution models for the second-order habitat selection and Bayesian spatial resource selection functions for the third-order habitat selection represent alternative approaches to studies of multi-scale habitat selection by animals. These analyses are unique because they do not need pseudo-absence locations, and they use model selection to provide an information-theoretical approach to hypothesis testing.

\section{Abbreviations}

AIC: Akaike information criterion; ATS: Advanced Telemetry Systems; BSRSF: Bayesian spatial resource selection function; CAR: conditional autocorrelative; Cl: confidence interval or credible interval; DIC: deviance information criterion; GPS: global positioning system; LULC: land use and land cover; MAXENT: maximum entropy; NLCD: National Land Cover Database; RSA: Redstone Arsenal; VHF: very high frequency; UTM: Universal Transverse Mercator.

\section{Acknowledgements}

The authors thank two anonymous reviewers for their constructive comments on our manuscript. We are grateful to Dr. D. Johnson for his assistance in the implementation of Bayesian spatial resource selection function. We thank Kyle Marable, Matthew McKinney, Cody Rainer, and Trent Danley for their volunteer assistance in radio-telemetry work.

\section{Authors' contributions}

GMW and JDT conceived and designed the study, LFM and GMW collected data, LFM and GMW analyzed the data, and GMW and JDT wrote the paper. All authors read and approved the final manuscript.

\section{Funding}

This study was financially supported by the United States Department of Agriculture APHIS National Wild life Research Center; and the Forest and Wildlife Research Center and Department of Wildlife, Fisheries and Aquaculture at Mississippi State University.

\section{Availability of data and materials}

The data and computational codes used in the current study are available from the corresponding author upon reasonable request.

\section{Ethics approval and consent to participate}

The study was approved by the Institutional Animal Care and Use Committee of the United States Department of Agriculture, National Wildlife Research Center (Protocol \#: QA-1626).

\section{Consent for publication}

Not applicable.

\section{Competing interests}

The authors declare that they have no competing interests.

\section{Author details}

${ }^{1}$ Department of Wildlife, Fisheries and Aquaculture, Mail Stop 9690, Mississippi State University, Mississippi State, MS 39762, USA. ${ }^{2}$ Present Address: United States Department of Agriculture West Virginia Farm Service Agency, 500 East
Main Street, Romney, WV 26757, USA. ${ }^{3}$ United States Department of Agriculture, Animal Plant Health Inspection Service, Wildlife Services, National Wildlife Research Center, Oregon Field Station, 321 Richardson Hall, Corvallis, OR 97333, USA.

Received: 25 February 2018 Accepted: 2 May 2019

Published online: 17 May 2019

\section{References}

1. Boyce MS. Scale for resource selection functions. Divers Distrib. 2006:12:269-76.

2. Johnson $\mathrm{DH}$. The comparison of usage and availability measurements for evaluating resource preference. Ecology. 1980;61:65-71.

3. Anderson DP, Turner MG, Forester JD, Zhu J, Boyce MS, Beyer H, Stowell L. Scale-dependent summer resource selection by reintroduced elk in Wisconsin, USA. J Wildl Manag. 2005;69:298-310.

4. Veron G, Patterson BD, Reeves R. Global diversity of mammals (Mammalia) in freshwater. Hydrobiologica. 2008:595:607-17.

5. Corriale MJ, Herrera EA. Patterns of habitat use and selection by the capybara (Hydrochoerus hydrochaeris): a landscape-scale analysis. Ecol Res. 2014;29:191-201.

6. Donkor NT, Fryxell JM. Lowland boreal forests characterization in Algonquin Provincial Park relative to beaver (Castor canadensis) foraging and edaphic factors. Plant Ecol. 2000;148:1-12.

7. Steyaert SM, Zedrosser A, Rosell F. Socio-ecological features other than sex affect habitat selection in the socially obligate monogamous Eurasian beaver. Oecologia. 2015;179:1023-32.

8. Zwolicki A, Pudełko R, Moskal K, Świderska J, Saath S, Weydmann A. The importance of spatial scale in habitat selection by European beaver. Ecography. 2019;42:187-200.

9. Hebblewhite M, Merrill EH. Trade-offs between predation risk and forage differ between migrant strategies in a migratory ungulate. Ecology. 2009:90:3445-54

10. Roberts TH, Arner DH. Food habits of beaver in east-central Mississippi. J Wildl Manag. 1984;48:1414-9.

11. Baker BW, Hill EP. Beaver (Castor canadensis). In: Feldhamer GA, Thompson BC, Chapman JA, editors. Wild mammals of North America: biology, management, and conservation. 2nd ed. Baltimore: Johns Hopkins University Press; 2003. p. 288-310

12. Collen P, Gibson RJ. The general ecology of beavers (Castor spp.), as related to their influence on stream ecosystems and riparian habitats, and the subsequent effects on fish-a review. Rev Fish Biol Fish. 2000;10:439-61.

13. Rosell F, Bozsér O, Collen P, Parker H. Ecological impact of beavers Castor fiber and Castor canadensis and their ability to modify ecosystems. Mammal Rev. 2005;35:248-76.

14. Barnes WJ, Dibble E. The effects of beaver in riverbank forest succession. Can J Bot. 1988:66:40-4

15. Townsend PA, Butler DR. Patterns of landscape use by beaver on the lower Roanoke River floodplain, North Carolina. Phys Geogr 1996:17:253-69.

16. Johnston CA, Naiman RJ. Boundary dynamics at the aquatic-terrestrial interface: the influence of beaver and geomorphology. Landsc Ecol. 1987; 1:47-57

17. Francis RA, Taylor JD, Dibble E, Strickland B, Petro VM, Easterwood C Wang G. Restricted cross-scale habitat selection by American beavers. Curr Zool. 2017;63:703-10.

18. Scrafford MA, Tyers DB, Patten DT, Sowell BF. Beaver habitat selection for 24 Yr since reintroduction north of Yellowstone National Park. Rangel Ecol Manag. 2018;71:266-73.

19. Touihri M, Labbé J, Imbeau L, Darveau M. North American beaver (Castor canadensis Kuhl) key habitat characteristics: review of the relative effects of geomorphology, food availability and anthropogenic infrastructure. Ecoscience 2018:25:9-23.

20. Holland AM, Schauber EM, Nielsen CK, Hellgren EC. Occupancy dynamics of semi-aquatic herbivores in riparian systems in Illinois, USA. Ecosphere. 2019;10:e02614. 
21. John F, Baker S, Kostkan V. Habitat selection of an expanding beaver (Castor fiber) population in central and upper Morava River basin. Eur J Wildl Res. 2010;56:663-71.

22. John F, Kostkan V. Compositional analysis and GPS/GIS for study of habitat selection by the European beaver, Castor fiber, in the middle reaches of the Morava River. Folia Zool. 2009;58:76.

23. Pinto B, Santos M, Rosell F. Habitat selection of the Eurasian beaver (Castor fiber) near its carrying capacity: an example from Norway. Can J Zool. 2009:87:317-25.

24. Lele SR, Merrill EH, Keim J, Boyce MS. Selection, use, choice and occupancy: clarifying concepts in resource selection studies. J Anim Ecol. 2013;82:1183-91.

25. Northrup JM, Hooten MB, Anderson CR, Wittemyer G. Practical guidance on characterizing availability in resource selection functions under a use-availability design. Ecology. 2013;94:1456-63.

26. Manly BFJ, McDonald LL, Thomas DL, McDonald TL, Erickson WP. Resource selection by animals: statistical design and analysis for field studies. 2nd ed. New York: Kluwer; 2002.

27. Laforge MP, Vander Wal E, Brook RK, Bayne EM, McLoughlin PD. Process-focussed, multi-grain resource selection functions. Ecol Model. 2015;305:10-21.

28. Aebischer NJ, Robertson PA, Kenward RE. Compositional analysis of habitat use from animal radio-tracking data. Ecology. 1993;74:1313-25.

29. Johnson DS, Hooten MB, Kuhn CE. Estimating animal resource selection from telemetry data using point process models. J Anim Ecol. 2013;82:1155-64.

30. Johnston CA, Windels SK. Using beaver works to estimate colony activity in boreal landscapes. J Wildl Manag. 2015;79:1072-80.

31. Mumma MA, Gillingham MP, Johnson CJ, Parker KL. Where beavers (Castor canadensis) build: Testing the influence of habitat quality, predation risk, and anthropogenic disturbance on colony occurrence. Can J Zool. 2018;96:897-904.

32. Fryxell JM. Habitat suitability and source-sink dynamics of beavers. J Anim Ecol. 2001;70:310-6.

33. Dupke C, Bonenfant C, Reineking B, Hable R, Zeppenfeld T, Ewald M, Heurich M. Habitat selection by a large herbivore at multiple spatial and temporal scales is primarily governed by food resources. Ecography. 2017:40:1014-27.

34. Haarberg O, Rosell F. Selective foraging on woody plant species by the Eurasian beaver (Castor fiber) in Telemark, Norway. J Zool. 2006;270:201-8.

35. Donkor NT, Fryxell JM. Impact of beaver foraging on structure of lowland boreal forests of Algonquin Provincial Park, Ontario. For Ecol Manag. 1999;118:83-92

36. Hartman G. Habitat selection by European beaver (Castor fiber) colonizing a boreal landscape. J Zool. 1996;240:317-25.
37. Beier P, Barrett RH. Beaver habitat use and impact in Truckee River basin, California. J Wildl Manag. 1987;51:794-9.

38. Naiman RJ, Johnston CA, Kelley JC. Alteration of North American streams by beaver. Bioscience. 1988;38:753-62.

39. McClintic LF, Taylor JD, Jones JC, Singleton RD, Wang G. Effects of spatiotemporal resource heterogeneity on home range size of American beaver. J Zool. 2014;293:134-41.

40. McClintic LF, Wang G, Taylor JD, Jones JC. Movement characteristics of American beavers (Castor canadensis). Behaviour. 2014;151:1249-65.

41. White GC, Garrott RA. Analysis of wildlife radio-tracking data. San Diego: Academic Press; 1990.

42. Cochran WW, Lord RD Jr. A radio-tracking system for wild animals. J Wild Manag. 1963;27:9-24.

43. Nams VO. Locate III user's guide. 3.34th ed. Tatamagouche: Pacer Computer Software; 2006. p. 2006.

44. Thomas DL, Taylor EJ. Study designs and tests for comparing resource use and availability. J Wildl Manag. 1990;54:322-30.

45. Thomas DL, Taylor EJ. Study designs and tests for comparing resource use and availability II. J Wild Manag. 2006;70:324-36.

46. Fry JA, Xian G, Suming J, Dewitz JA, Homer CG, Limin Y, Barnes CA, Herold ND, Wickham JD. Completion of the 2006 National Land Cover Database for the conterminous United States. Photogramm Eng Remote Sens. 2011;77:858-64.

47. Hirzel A, Hausser J, Perrin N. Biomapper 3.2. In: Biomapper 32. Laboratory of Conservation Biology, Department of Ecology and Evolution, University of Lausanne, Lausanne, Switzerland. http://www.unil.ch/biomapper; 2005.

48. de Valpine P, Harmon-Threatt AN. General models for resource use or other compositional count data using the Dirichlet-multinomial distribution. Ecology. 2013;94:2678-87.

49. Besag J. Spatial interaction and the statistical analysis of lattice systems. J R Stat Soc B. 1974;36:192-236.

50. Blangiardo M, Cameletti M, Baio G, Rue H. Spatial and spatio-temporal models with R-INLA. Spat Spatio-temporal Epidemiol. 2013;4:33-49.

51. Rue H, Martino S, Chopin N. Approximate Bayesian inference for latent Gaussian models by using integrated nested Laplace approximations. J R Stat Soc Ser B Stat Methodol. 2009;71:319-92.

52. Spiegelhalter DJ, Best NG, Carlin BR, van der Linde A. Bayesian measures of model complexity and fit. J R Stat Soc Ser B Stat Methodol. 2002;64:583-616.

\section{Publisher's Note}

Springer Nature remains neutral with regard to jurisdictional claims in published maps and institutional affiliations.
Ready to submit your research? Choose BMC and benefit from:

- fast, convenient online submission

- thorough peer review by experienced researchers in your field

- rapid publication on acceptance

- support for research data, including large and complex data types

- gold Open Access which fosters wider collaboration and increased citations

- maximum visibility for your research: over 100M website views per year

At BMC, research is always in progress.

Learn more biomedcentral.com/submissions 